OPEN ACCESS

Check for updates

\title{
Public sector financial support for late stage discovery of new drugs in the United States: cohort study
}

\author{
Rahul K Nayak, ${ }^{1}$ Jerry Avorn, ${ }^{1}$ Aaron S Kesselheim ${ }^{1}$
}

${ }^{1}$ Program On Regulation,

Therapeutics, And Law

(PORTAL), Division of

Pharmacoepidemiology

and Pharmacoeconomics,

Department of Medicine,

Brigham and Women's Hospital

and Harvard Medical School,

1620 Tremont Street, Boston,

MA 02120, USA

Correspondence to:

A S Kesselheim

akesselheim@bwh.harvard.edu

(or @akesselheim on Twitter;

ORCID 0000-0002-8867-2666)

Additional material is published online only. To view please visit the journal online.

Cite this as: BMJ 2019;367:15766 http://dx.doi.org/10.1136/bmj.15766

Accepted: 23 September 2019

\author{
ABSTRACT \\ OBJECTIVE \\ To determine the extent to which late stage \\ development of new drugs relies on support from \\ public funding. \\ DESIGN \\ Cohort study. \\ SETTING
}

All new drugs containing one or more new molecular entities approved by the US Food and Drug

Administration (FDA) between January 2008 and

December 2017 via the new drug application pathway.

\section{MAIN OUTCOME MEASURES}

Patents or drug development histories documenting

late stage research contributions by a public sector

research institution or a spin-off company, as well as each drug's regulatory approval pathway and first-inclass designation.

\section{RESULTS}

Over the 10 year study period, the FDA approved 248 drugs containing one or more new molecular entities. Of these drugs, 48 (19\%) had origins in publicly supported research and development and 14 (6\%) originated in companies spun off from a publicly supported research program. Drugs in these groups were more likely to receive expedited FDA approval ( $68 \%$ v $47 \%, \mathrm{P}=0.005)$ or be designated first in class ( $45 \% \vee 26 \%, P=0.007)$, indicating therapeutic importance.

\section{CONCLUSIONS}

A review of the patents associated with new drugs approved over the past decade indicates that publicly supported research had a major role in the late stage development of at least one in four new drugs,

\section{WHAT IS ALREADY KNOWN ON THIS TOPIC}

Publicly sponsored research has a substantial role in the upstream, basic science investigations behind most new drugs

About $14 \%$ of new molecular entities approved in 1990-2007 had late stage, patentable contributions from a public sector research institution

\section{WHAT THIS STUDY ADDS}

Among 248 new small molecule drugs approved by the US Food and Drug Administration in 2008-17 containing a new molecular entity, $25 \%$ had key late stage research contributions from public sector research institutions (19\%) or spin-off companies from one of these institutions (6\%), often with key patents on the drug credited in part to these institutions

These publicly sponsored drugs were more likely to receive expedited regulatory designation and be first in class, suggesting high therapeutic importance

Publicly sponsored research has a substantial and growing role in late stage drug discovery and development, and this information can inform policies related to drug pricing and fair compensation for public sector investment. either through direct funding of late stage research or through spin-off companies created from public sector research institutions. These findings could have implications for policy makers in determining fair prices and revenue flows for these products.

\section{Introduction}

Public sector support funds much biomedical research conducted at universities, academic medical centers, other non-profit organizations, and government laboratories. In the United States, such support comes primarily from the National Institutes of Health (NIH), but also from other federal or state entities, disease focused charities (eg, the Cystic Fibrosis Foundation), or biomedical research philanthropies (eg, the Howard Hughes Medical Institute). Such research often has a key role in elucidating potential drug targets and understanding the pathophysiology of disease-activities that are central to drug discovery. This costly upstream research could stretch back several decades before a drug reaches clinical trials or is approved by the US Food and Drug Administration or another regulator. ${ }^{1}$ One recent report found that NIH funding contributed to published research associated with all 210 new drugs approved by the FDA in 2010-16. ${ }^{2}$ However, public support often funds later stage translational research as well, and might also cover the conduct of some clinical trials required for drug approval. At some point in the development cycle of most prescription drugs, pharmaceutical manufacturers become involved and often expend substantial resources in moving drugs through pivotal clinical trials and FDA approval and in developing means of large scale production. For some new drugs, their investigation, discovery, and development occur entirely within the corporate sector, but this is uncommon.

The role of public sector contributions versus those of the pharmaceutical industry to drug discovery remains a point of controversy, with some arguing that companies' investment in drug discovery is the key source for new drug development. ${ }^{3}$ This view, along with the costs of conducting clinical trials, is used to justify high drug prices, ${ }^{4-6}$ although the actual cost of drug development is difficult to accurately estimate. ${ }^{7}$ The relative contributions of publicly supported research and the pharmaceutical industry can be difficult to separate for a particular product. However, the upstream, pre-competitive, basic science research that so many new drugs depend on is generally thought to be predominantly funded by public support, while clinical trials are generally thought to be predominantly funded by the pharmaceutical industry.

One way to assess the contributions of various sectors in the drug development continuum is to 
define the research that justifies patent claims on the drug-the basis of drug ownership and pricing. Patent-generating research tends to occur later in development because patent law requires inventors to describe a well defined product or process before a patent can be issued. Other patentable steps can cover a drug's synthesis, the chemical composition of its active ingredient, or its method of use. Patents provide the basis for market exclusivity, granting the patent holder ownership over the product and therefore the capacity to control the drug's US price, as well as considerable leverage in pricing negotiations in other healthcare systems. Although patents enable a manufacturer to demand high drug prices, patent based levers have been proposed, and occasionally have been used with success, to achieve public policy goals, such as helping ensure access to essential drugs in low income settings. . $^{8-12}$

Previous studies have reviewed the data submitted to the FDA to investigate public sector research support of drug development that is reflected in these patents. Although some follow-on patents are clinically trivial and not germane to a drug's innovative contribution to patient care, the patents submitted to FDA are typically those that are considered key to the drug's invention and clinical use. Earlier analyses found public sector research institutions to be associated with the patents covering $4.6 \%$ of new molecular entities approved in $1981-90,{ }^{13} 6.7 \%$ of new drugs approved in 1990-99, ${ }^{4}$ $9.0 \%$ of new molecular entities approved in 1988$2005,{ }^{14}$ and, most recently, $13.6 \%$ of new molecular entities approved between 1990-2007. ${ }^{15}$ This increase in the proportion of publicly supported research contributions has been attributed to the changing nature of drug development, with large manufacturers investing proportionally less in internal basic and translational research themselves. ${ }^{15}$

Biomedical research support from the public sector has continued to grow in recent decades, although until recently it had fallen in inflation adjusted terms. By contrast, more large pharmaceutical manufacturers have focused on purchasing drugs developed in startup companies, many spun out of public sector research institutions. We therefore sought to examine the extent of publicly supported research for new FDA approved drugs as reflected in patent data from 2008-17, including the role of start-up biotechnology companies emerging from publicly supported research.

\section{Methods}

To identify recently approved drugs originating from publicly supported research, we examined patent data listed with the FDA, using an approach similar to that used in previous studies. ${ }^{4}{ }^{13-15}$ The FDA's Orange Book describes the key US patents that have been granted for a drug substance (active ingredient), drug product (formulation and composition), or method of use. The Orange Book does not include other patents that might be held on the drug, such as those on manufacturing processes, although public sector institutions are less likely to contribute to these patents. It also does not include non-US patents or patents that have expired.

The Orange Book could miss patents that expired before drug approval, or intellectual contributions that were never patented, so we used additional data sources to supplement our analysis. The Merck Index, a chemical entity reference, was searched for supplementary patent information. The index generally lists one or two of the most important patents on a given drug, usually on the final formulation of the active ingredient. For many drugs, the Merck Index patent(s) were the same as those found in the Orange Book. Patents that were listed in the Merck Index alone typically had expired before drug approval and therefore were not included in the Orange Book.

The patent data available through these sources does not comprehensively capture all patents on a drug and can underestimate non-patent-based intellectual contributions to new drug discovery, particularly in circumstances where patents were not pursued. Therefore, we also used drug discovery histories to identify key missing intellectual contributions. We used the drug monograph database AdisInsight, as well as our own investigations, as described in detail below.

\section{Data collection}

Drug approval

We identified all new drugs approved by the US FDA between 2008 and 2017 using the Drugs@FDA database, ${ }^{16}$ including all drugs approved through the new drug application process for small (that is, nonbiological) molecular entities. Biological treatments, vaccines, and gene treatments were excluded because they are approved through a separate biological license application pathway for which patent information is not collected by the FDA. Novel drugs were identified based on the FDA's type 1 approval designation (drug products containing a new molecular entity) and FDA lists of new drug approvals by year. ${ }^{1}$ Treatment categorisation was assigned on the basis of the drug's initial FDA approved indication.

\section{Approval pathway}

We defined a drug's approval pathway using FDA listings of drugs that received standard, priority, accelerated, breakthrough, fast track, first-in-class, or Orphan Drug Act designation; a drug may have received more than one of these definitions. We considered such designations only for a drug's initial approval. In 2008-10, the FDA did not publish fast track designation or classify drugs as first-in-class on their website. For those years, we used other published databases. ${ }^{17} 18$ A full list of drugs included in this study and their FDA approval pathways is included in supplementary table S1.

\section{Patents}

As described above, we then obtained patent data for each approved drug from several sources. We issued a Freedom of Information Act request to obtain 
historical Approved Drug Products with Therapeutic Equivalence Evaluations (Orange Book) data files for 2001-17 that, along with a data file from March 2018, were used to obtain patent data submitted to the FDA, including those that might have expired. Since patents can be added after drug approval, we also conducted a manual search of the Orange Book for drugs with no patents listed in data files as of April 2019 and found one additional drug with a patent added by the manufacturer. The FDA requires that certain key patents be submitted by the manufacturer for inclusion in the Orange Book, including patents on the drug's substance (active ingredient), product (formulation and composition), or method of use. The Merck Index was used to supplement patent information and typically listed one or two key patents related to the drug's active ingredient (final formulation) or synthesis. $^{19}$

We next obtained data about the patents granted for the study drugs by using the PatentsView application programing interface developed by the US Patent and Trademark Office and the PatentsView R package, using the programming language $R$ version 3.5.0. ${ }^{20} 21$ This process allowed identification of a patent's inventor and the organization that was assigned ownership. Typically, these data reflect the information that was assigned at time of the patent grant. This method would not identify information, such as disclosure of government funding, that was later corrected. We manually investigated patents which could not be queried using this method to determine the inventor and assigned ownership for each product.

\section{Drug monographs}

Examining only the patent information from the Orange Book could provide an incomplete definition of the key contributions to a drug's invention if key patents expired before drug approval. We used the Merck Index to identify these patents, although such an approach would miss important contributions in cases in which a patent was intentionally not pursued. Previous studies have used bibliometric approaches to capture public supported research contributions by examining publications or patent citation. ${ }^{214}$ For example, Cleary et al found every drug approved from 2010-16 had associated NIH funding contributing to published research. ${ }^{2}$ But these approaches capture the substantial role of public research on the upstream, basic science research that underpins drug discovery. In this paper, we focus on the later stage contributions by public sector institutions.

We therefore supplemented the patent analyses with the drug monograph database, AdisInsight, which detailsadrug's discoveryhistory, preclinicaland clinical development, regulatory status, and pharmacological properties. To develop the monograph, researchers examine the relevant scientific publications, patents, news media, financial transactions, and regulatory documents to create an expert summary of the drug's development history. AdisInsight then creates a descriptive narrative of the research and development history and assigns classifications of "originators" and "developers" for each drug. The originator usually refers to the institution that AdisInsight reviewers concluded originally invented or discovered the active ingredient, and developers were any institution that helped with conducting, funding, or supporting the clinical trials. Given our interest in the role of late stage research contributions, we focused on the drugs that were listed as originating from publicly supported research institutions.

Because the AdisInsight methodology is proprietary and does not provide explanations for why a monograph classified an institution in a given way, we further studied any drug that listed a publicly supported research institution as an originator in the AdisInsight listing if no Orange Book or Merck Index patent was assigned to that institution. We began with targeted web searches to verify the connection between the drug and the AdisInsight listed originating institution. One author (RKN) searched for evidence of news articles, university press releases, researchers' academic profiles, scientific publications, US Securities and Exchange Commission (SEC) filings, and patents that confirmed that the drug's discovery or development had late stage research contributions from the institution (that is, intellectual contributions similar to a patentable invention, such as the drug's discovery or invention, or method of synthesis). If we found corroborating evidence, we considered the AdisInsight classification to be verified, confirming that the drug was based on publicly supported research contributions, as described further below. In one case, we were unable to corroborate the connection, and did not classify the drug as having a publicly supported research origin.

\section{Drug development histories}

Similar to the approach used to verify entries from AdisInsight, we conducted web searches to investigate the development history for each drug in the study. We examined publications focused on drug development (eg, Nature Reviews Drug Discovery), researcher or inventor biography pages, news articles, academic technology transfer sites, and Wikipedia entries to identify other late stage research contributions supported by public funds that were not captured in the process above. Because we found evidence for publicly supported research institutions' involvement from our initial web searches, we then conducted targeted searches for the drug and the possible researchers and institutions involved to seek primary academic publications, news media sources, or SEC filings that could verify the public sector institution's role.

\section{Identifying public sector research institutions and spin-off companies}

To better understand the development pathway for each drug, we examined the assignee information for each patent (or institution identified from the drug monograph and development history investigations) and conducted web searches to classify the organi- 
zation as either a public sector research institution (universities, hospitals, non-profit foundations or institutions, or government laboratories) or a private, non-public organization (primarily biotechnology or pharmaceutical companies). For cases in which a patent had multiple assignees, we characterized the patent as held by a public sector research institution if one or more of the assignees was a public sector institution.

Whenever possible, we identified start-up firms spun out from publicly supported research institutions. For each company, we investigated the foundational history using web searches of the company's website, new articles about the company, Wikipedia entries, SEC filings, and profiles of the company or its founders. Indications that the company was spun out from a publicly supported research institution were followed up to confirm or refute such a connection. For example, we reviewed the company's own description of its founding, university press releases, and university profiles of the academic founder to determine whether the company could fairly be described as an academic spin-off company. Although we identified many companies that were spun out from public sector research institutions, this did not automatically mean the drug in question was based on publicly supported research. To ensure accurate categorization, we investigated whether the FDA approved drug was based on the same technologies or products that had led to the formation of the spinoff company, to characterize whether the drug truly could be considered as being based on an extension of publicly supported research.

\section{Data analysis}

Determining public sector contributions

To determine whether a drug had a major research contribution from publicly supported research late in its development, we further analyzed the contributions of the institutions involved in the development. We considered a drug to have been based on public support if we found any patents for the product that were owned by a public sector research institution or that declared government funding for the product (that is, a government interest statement). We also included drugs listed in the drug monograph database as "originating" in a public sector research institution that we could independently verify as well as from our own review of drug development histories as described above. For drugs that were included without patent data, all authors reviewed and agreed with the drug's classification of having late stage, publicly sponsored research contribution. For a combination drug containing a new molecular entity (eg, antiviral treatments), we considered the drug to have contributions from publicly supported research if one or more of the active ingredients had contributions from a publicly supported research, consistent with the approach taken by Stevens et al. ${ }^{15}$

For spin-off companies, as described above, if we found evidence that a drug was based on the same technology or innovation that led to the creation of the company, we classified the drug as having a late stage research contribution from a spin-off company that had its origin in publicly supported research. We excluded drugs that were unrelated to a company's original spin-off product or technology.

Many aspects of a drug can be patented, with some patents representing more important innovation than others. Firstly, for each drug in which one or more patents were central to identifying a publicly sponsored research contribution, we calculated the share of patents held by publicly supported research institutions and their spin-off companies, compared with the total patents identified for that drug. We report below the unweighted average of the share of patents held by publicly supported research institutions and their spin-off companies, with a 95\% confidence interval assuming a normal distribution. Secondly, we determined whether the oldest patent identified was held by a publicly supported research institution or a spin-off company. Thirdly, we examined all the Orange Book patents for that drug to determine whether publicly supported research led to patents on its substance (active ingredient) or product (formulation and composition), which are typically more foundational.

To analyze whether drugs based on publicly sponsored research or spin-off contributions were significantly more likely to have been granted expedited FDA review or be a first-in-class drug, we conducted a Fisher's exact test of independence with a Bonferroni adjusted alpha level of $0.007(0.05 / 7)$.

\section{Patient and public involvement}

While we recognize that patients and members of the public are the ultimate stakeholders and end users in late stage new drug discovery, we were unable to involve them as partners in considering the research question, the analysis, or the outcomes. The analysis required in-depth legal and specialist knowledge with access to large databases. We plan to make the published information available to key public interest and advocacy groups to further transparency around the pathways to late stage new drug discovery.

\section{Results}

\section{Patent and originator information}

We identified 248 novel drugs that represented new molecular entities approved for the first time between January 2008 and December 2017 (21 were combinations, of which some had more than one new molecular entity, leading to 253 new molecular entities). Using the FDA Orange Book, we identified at least one patent for 230 (93\%) products. The Merck Index identified at least one patent for an additional $14(6 \%)$ products, leaving only five products (2\%) with no available patent information. We identified drug monographs for 246 (99\%) products, and either patent or monograph data were available for all but one drug $(n=247)$. 
Publicly supported research contributions

Our review of patents and supporting data found that a quarter $(n=62)$ of all new products had documented late stage research contributions from a publicly supported research institution or spin-off company. Forty eight products (19\% of all new drug approvals) had evidence of direct publicly supported research (table 1 and table 2). For all but one, the contributions were related to the drug's initial discovery, synthesis, or other key intellectual property leading to a patentable invention. For 30 of these drugs, publicly supported research institutions directly held one or more of the key patents. Another seven drugs had direct publicly supported research origins, although the patents listed in the Orange Book were held by a spin-off company. The remainder of drugs with public support contributions was found through the drug monograph database and investigations of the drugs' discovery and development histories. One of these drugs, benznidazole, a treatment for Chagas disease, is a distinct case because it received development support from the Drugs for Neglected Diseases Initiative and others, and is being sold on a "no profit no loss" basis. ${ }^{22}$ However, the drug was originally developed by Hoffman-La Roche in the 1970s, which then donated the rights to the drug to the Brazilian government in $2003 .^{23}$

Fourteen $(6 \%)$ drugs were developed by spinoff companies that were based wholly or in part on publicly supported research; all but two were identified through patents listed in the Orange Book (table 3). For example, the hepatitis C treatment sofosbuvir (Sovaldi) and other sofosbuvir-containing

\begin{tabular}{|c|c|c|c|c|c|}
\hline Approval date (ID) & Drug name (generic) & Manufacturer & Public sector institution & $\begin{array}{l}\text { US government } \\
\text { contribution* }\end{array}$ & $\begin{array}{l}\text { Source used } \\
\text { for origin }\end{array}$ \\
\hline 20 March 2008 (\#022249) & $\begin{array}{l}\text { Bendamustine } \\
\text { hydrochloride }\end{array}$ & Cephalon & $\begin{array}{l}\text { Institute for Microbiology and } \\
\text { Experimental Therapy } \\
\text { (former East Germany) }\end{array}$ & - & Drug history \\
\hline 24 April 2008 (\#021964) & Methylnaltrexone bromide & Salix Pharms & University of Chicago (PHS/HHS) & Yes & Patent \\
\hline 3 July 2008 (\#022090) & Gadoxetate disodium & Bayer Healthcare & Massachusetts General Hospital & - & AdisInsight \\
\hline 19 September 2008 (\#022290) & Iobenguane sulfate 123 | & GE Healthcare & University of Michigan & Yes & Patent (Merck Index) \\
\hline 28 October 2008 (\#022253) & Lacosamide & UCB & $\begin{array}{l}\text { University of Houston/Research } \\
\text { Corporation Technologies (NIH) }\end{array}$ & Yes & Patent, AdisInsight \\
\hline 15 December 2008 (\#022311) & Plerixafor & Genzyme & Rega Institute for Medical Research & - & AdisInsight \\
\hline 22 December 2008 (\#021711) & Gadofosveset trisodium & Lantheus Medical & Massachusetts General Hospital & - & $\begin{array}{l}\text { Patent, } \\
\text { AdisInsight }\end{array}$ \\
\hline 7 April 2009 (\#022268) & Artemether, lumefantrinet & Novartis & $\begin{array}{l}\text { Institute of Microbiology and } \\
\text { Epidemiology, Academy of Military } \\
\text { Medical Sciences (China) }\end{array}$ & Yes & Patent \\
\hline 24 September 2009 (\#022468) & Pralatrexate & Allos & $\begin{array}{l}\text { Sloan-Kettering Institute for Cancer } \\
\text { Research, SRI International, Southern } \\
\text { Research Institute (NCI) }\end{array}$ & Yes & Patent \\
\hline 5 November 2009 (\#022393) & Romidepsin & Celgene & Harvard University/University of Tokyo & - & Drug history \\
\hline 16 November 2009 (\#022395) & Capsaicin & Acorda & University of California & - & Patent \\
\hline 22 January $2010(\# 022250)$ & Fampridine & Acorda & Purdue University & - & Drug history \\
\hline 13 August 2010 (\#022474) & Ulipristal acetate & Lab HRA Pharma & HHS/Research Triangle Institute & Yes & Patent \\
\hline 15 November 2010 (\#201532) & Eribulin mesylate & Eisai & Harvard University/NCl & Yes (no patent) & $\begin{array}{l}\text { AdisInsight, drug } \\
\text { history }\end{array}$ \\
\hline 28 April 2011 (\#202379) & Abiraterone acetate & Janssen Biotech & $\begin{array}{l}\text { Institute of Cancer Research (UK)/ } \\
\text { University of London }\end{array}$ & - & Patent, AdisInsight \\
\hline 2 May 2011 (\#201280) & Linagliptin & $\begin{array}{l}\text { Boehringer } \\
\text { Ingelheim }\end{array}$ & $\begin{array}{l}\text { University of Toronto, Tufts College, New } \\
\text { England Medical Center Hospitals (NIH) }\end{array}$ & Yes & Patent \\
\hline 14 October 2011 (\#021825) & Deferiprone & Apopharma & $\begin{array}{l}\text { Royal Free and University College } \\
\text { Medical School/University of Toronto }\end{array}$ & - & $\begin{array}{l}\text { Patent, AdisInsight, } \\
\text { drug history }\end{array}$ \\
\hline 23 January 2012 (\#202833) & Ingenol mebutate & Leo Labs & $\begin{array}{l}\mathrm{NCl} \text { (US)/University of Queensland } \\
\text { (Australia) }\end{array}$ & Yes (no patent) & $\begin{array}{l}\text { Patent, AdisInsight, } \\
\text { drug history }\end{array}$ \\
\hline 31 January 2012 (\#203188) & Ivacaftor & Vertex Pharms & Cystic Fibrosis Foundation Therapeutics & - & AdisInsight \\
\hline 6 March $2012(\# 021746)$ & Lucinactant & Windtree Therapeutics & Scripps Research Institute & - & Patent \\
\hline 6 April 2012 (\#202008) & Florbetapir 18F & Avid Radiopharms & University of Pennsylvania (NIH) & Yes & Patent \\
\hline 27 August 2012 (\#203100) & $\begin{array}{l}\text { Cobicistat, elvitegravir, } \\
\text { emtricitabinef, tenofovir } \\
\text { disoproxil fumarate }\end{array}$ & Gilead Sciences & Emory University (NIH) & Yes & Patent \\
\hline 31 August 2012 (\#203415) & Enzalutamide & Astellas & University of California (US Army, NIH) & Yes & Patent \\
\hline 12 September 2012 (\#203155) & Choline 11C & MCPRF & Mayo Clinic & - & Drug history \\
\hline 21 December 2012 (\#203441) & Teduglutide recombinant & NPS Pharms & $\begin{array}{l}\text { Toronto General Hospital, University of } \\
\text { Toronto }\end{array}$ & - & Patent, AdisInsight \\
\hline 21 December 2012 (\#203858) & Lomitapide mesylate & Aegerion & University of Pennsylvania & - & Patent \\
\hline \multicolumn{6}{|c|}{$\begin{array}{l}\mathrm{NIH=National} \mathrm{Institutes} \mathrm{of} \mathrm{Health;} \mathrm{NCI}=\text { National Cancer Institute; PHS=US Public Health Service; HHS=US Department of Health and Human Services. } \\
\text { *Considered to have US government contributions if the drug originated at a US government lab, a patent was assigned to a US government agency, or a patent declared US government funding } \\
\text { of the invention. Two drugs had origins with the National Cancer Institute, although no patents were found to be held by the NCI. } \\
\text { tArtemether and lumefantrine are both new molecular entities with publicly supported origins, but are counted as one product in this analysis. } \\
\text { fThis combination product contains the new molecular entity elvitegravir, but it is included as having a publicly supported origin because emtricitabine originated at Emory. This product } \\
\text { represented the first time elvitegravir was approved by the US Food and Drug Administration. }\end{array}$} \\
\hline
\end{tabular}


combination drugs were in this category because they originated at Pharmasset, a spin-off company based on federally funded research performed at Emory University. ${ }^{24}$ In addition to these 14 drugs, at least 10 other drugs had origins in spin-off companies, but these were excluded because it was unclear whether these drugs were related to the technologies or drugs that initially gave rise to the spin-off company. Full details of the rationale used to classify drugs as having publicly supported or spin-off research contributions can be found in appendix 1 .

We identified most of the drugs that had publicly sponsored research or spin-off contributions through patent data available through the Orange Book $(n=47)$. Two were found from patents in the Merck Index, while eight came from the drug monograph classification and five from our own drug history investigations. The contributions of each of the date sources are shown in figure 1. The data sources had strong concordance (appendix 2).

\section{Contributions by drug class}

Late stage, publicly supported research contributions by drug class were concordant with the overall total number of approvals by drug class (table S2). In hematology-oncology, 17 (27\%) drugs were based on publicly supported research; 13 (33\%) drugs were in infectious diseases, and $10(63 \%)$ were among diagnostics agents Each of these drug classes had a higher share of drugs from publicly supported research than the average in our sample. Conversely, for psychiatric drugs, we did not find late stage, publicly supported research contributions for any of the 15 recently approved drugs.

\section{Patent characteristics}

Of the 48 drugs identified as having late stage, publicly supported research contributions, 38 (80\%) had at least one patent held by a publicly supported research institution or spin-off company. For these drugs, 70\% (95\% confidence interval $60 \%$ to $81 \%$ ) of the patents, on average, were held by a publicly supported research institution or spin-off (table 4). A US government interest statement was declared on at least one patent in the case of 17 drugs. For 32 (84\%) drugs, the oldest patent identified was held by a publicly supported research institution or spin-off company. Of the 35 drugs for which we identified at least one Orange

\begin{tabular}{|c|c|c|c|c|c|}
\hline Approval date (ID) & Drug name (generic) & Manufacturer & Public sector institution & $\begin{array}{l}\text { US government } \\
\text { contribution* }\end{array}$ & $\begin{array}{l}\text { Source used } \\
\text { for origin }\end{array}$ \\
\hline 25 January 2013 (\#022271) & Alogliptin benzoate & Takeda Pharms USA & $\begin{array}{l}\text { University of Toronto, Tufts College, } \\
\text { New England Medical Center Hospitals (NIH) }\end{array}$ & Yes & Patent \\
\hline 13 March 2013 (\#202207) & $\begin{array}{l}\text { Technetium } 99 \mathrm{mTc} \\
\text { tilmanocept }\end{array}$ & Cardinal Health 414 & University of California-San Diego (NIH) & Yes & Patent \\
\hline 25 October 2013 (\#203137) & Flutemetamol 18F & GE Healthcare & University of Pittsburgh & - & Patent \\
\hline 19 March 2014 (\#204684) & Miltefosine & Knight Therapeutics & Max Planck Institute (Germany) & - & Patent (Merck index) \\
\hline 19 March 2014 (\#204677) & Florbetaben $18 \mathrm{~F}$ & Piramal Imaging & University of Pennsylvania (NIH) & Yes & Patent \\
\hline 19 August 2014 (\#205494) & Eliglustat tartrate & Genzyme & University of Michigan $(\mathrm{NIH})$ & Yes & Patent \\
\hline 19 December 2014 (\#206162) & Olaparib & Astrazeneca Pharms & $\begin{array}{l}\text { University of Sheffield/Yorkshire Cancer } \\
\text { Research/Institute of Cancer } \\
\text { Research/University of Cambridge (UK) }\end{array}$ & - & Patent, AdisInsight \\
\hline 19 December 2014 (\#206426) & Peramivir & Biocryst & University of Alabama-Birmingham & - & Patent, AdisInsight \\
\hline 29 April 2015 (\#206333) & Deoxycholic acid & Kythera Biopharms & University of California-Los Angeles & - & Patent \\
\hline 2 July 2015 (\#206038) & Ivacaftor, lumacaftor & Vertex Pharms & Cystic Fibrosis Foundation Therapeutics & - & AdisInsight \\
\hline 23 October 2015 (\#207953) & Trabectedin & Janssen Prods & University of Illinois & - & AdisInsight \\
\hline 5 November 2015 (\#207561) & $\begin{array}{l}\text { Cobicistat, elvitegravir, } \\
\text { emtricitabinet, tenofovir } \\
\text { alafenamide fumarate }\end{array}$ & Gilead Sciences & Emory (NIH) & Yes & Patent \\
\hline 11 April 2016 (\#208573) & Venetoclax & Abbvie & $\begin{array}{l}\text { Walter and Eliza Hall Institute of Medical } \\
\text { Research }\end{array}$ & - & Patent \\
\hline 27 May $2016(\# 208054)$ & Fluciclovine $18 \mathrm{~F}$ & Blue Earth & Emory University (Department of Energy) & Yes & Patent \\
\hline 29 May 2016 (\#207999) & Obeticholic acid & Intercept Pharms & University of Perugia (Italy) & - & Patent, AdisInsight \\
\hline 19 September 2016 (\#206488) & Eteplirsen & Sarepta Therapeutics & $\begin{array}{l}\text { Leiden University Medical Center } \\
\text { (Netherlands)/University of Western Australia }\end{array}$ & - & Patent \\
\hline 19 December 2016 (\#209115) & Rucaparib camsylate & Clovis Oncology & Newcastle University (UK)/Cancer Research UK & - & Patent \\
\hline 23 December 2016 (\#209531) & Nusinersen sodium & Biogen Idec & $\begin{array}{l}\text { University of Massachusetts (NIH)/ Cold Spring } \\
\text { Harbor Laboratory }\end{array}$ & Yes & Patent \\
\hline 29 April 2017 (\#207997) & Midostaurin & Novartis Pharms & Dana Farber Cancer Institute & - & Patent \\
\hline 29 August 2017 (\#209570) & Benznidazole $\neq$ & Chemo Research SL & $\begin{array}{l}\text { Brazilian government, Drugs for Neglected } \\
\text { Diseases Initiative Foundation }\end{array}$ & - & Drug history \\
\hline 18 December 2017 (\#208254) & Netarsudil dimesylate & Aerie Pharms & Duke University & - & Patent, AdisInsight \\
\hline 21 December 2017 (\#209360) & Angiotensin II acetate & La Jolla Pharm & George Washington University & - & Patent \\
\hline
\end{tabular}

$\mathrm{NIH}=$ National Institutes of Health.

${ }^{\star}$ Considered to have US government contributions if the drug originated at a US government lab, a patent was assigned to a US government agency, or a patent declared US government funding of the invention. Two drugs had origins with the National Cancer Institute, although no patents were found to be held by the NCl.

tThis combination product contains the new molecular entity tenofovir alafenamide fumarate, but it is included as having a publicly supported origin because emtricitabine originated at Emory. This product represented the first time tenofovir alafenamide fumarate was approved by the US Food and Drug Administration.

¥Benzinidazole represents a distinct case; it was discovered through research at Hoffman-LaRoche and not through publicly supported research. However, Hoffman-LaRoche donated the rights to the drug to the Brazilian government. In addition, the Drug for Neglected Diseases Initiative Foundation supported the development and Food and Drug Administration approval of the drug in the US and is being sold on a "no profit no loss" bas bis $^{2} 2$ 


\begin{tabular}{|c|c|c|c|c|c|}
\hline $\begin{array}{l}\text { Approval } \\
\text { date (ID) }\end{array}$ & Drug name (generic) & Manufacturer & Spin-off company & Public sector institution & Source \\
\hline $\begin{array}{l}1 / 18 / 2008 \\
(\# 022187)\end{array}$ & Etravirine* & Janssen $\mathrm{R}$ and $\mathrm{D}$ & Tibotec & Rega Institute & $\begin{array}{l}\text { Patent, } \\
\text { AdisInsight }\end{array}$ \\
\hline $\begin{array}{l}1 / 14 / 2011 \\
(\# 022454)\end{array}$ & Ioflupane $123 \mid$ & GE Healthcare & $\begin{array}{l}\text { Research Biochemicals } \\
\text { International }\end{array}$ & Northeastern University & Patent \\
\hline $\begin{array}{l}5 / 20 / 2011 \\
(\# 202022)\end{array}$ & $\begin{array}{l}\text { Rilpivirine } \\
\text { hydrochloride* }^{*}\end{array}$ & Janssen Prods & Tibotec & Rega Institute & $\begin{array}{l}\text { Patent, } \\
\text { AdisInsight }\end{array}$ \\
\hline $\begin{array}{l}8 / 17 / 2011 \\
(\# 202429)\end{array}$ & Vemurafenib & Hoffmann-La Roche & Plexxikon & $\begin{array}{l}\text { Yale University/University } \\
\text { of California-Berkeley }\end{array}$ & Patent \\
\hline $\begin{array}{l}7 / 20 / 2012 \\
(\# 202714)\end{array}$ & Carfilzomib & Onyx Therapeutics & Proteolix & $\begin{array}{l}\text { Yale University/California } \\
\text { Institute of Technology }\end{array}$ & Patent \\
\hline $\begin{array}{l}8 / 30 / 2012 \\
(\# 202811)\end{array}$ & Linaclotide & Allergan Sales & Microbia & Whitehead Institute & Patent \\
\hline $\begin{array}{l}5 / 15 / 2013 \\
(\# 203971)\end{array}$ & $\begin{array}{l}\text { Radium 223Ra } \\
\text { dichloride }\end{array}$ & Bayer Healthcare & $\begin{array}{l}\text { Anticancer Therapeutic } \\
\text { Inventions }\end{array}$ & $\begin{array}{l}\text { Norwegian Radium Hospital, } \\
\text { University of Oslo }\end{array}$ & Patent \\
\hline $\begin{array}{l}12 / 6 / 2013 \\
(\# 204671)\end{array}$ & Sofosbuvir & Gilead Sciences & Pharmasset & Emory University & Patent \\
\hline $\begin{array}{l}7 / 7 / 2014 \\
(\# 204427)\end{array}$ & Tavaborole & Anacor Pharms & Anacor Pharmaceuticals & $\begin{array}{l}\text { Stanford University/ } \\
\text { Pennsylvania State University }\end{array}$ & Patent \\
\hline $\begin{array}{l}10 / 10 / 2014 \\
(\# 205834)\end{array}$ & $\begin{array}{l}\text { Ledipasvirt, } \\
\text { sofosbuvir }\end{array}$ & Gilead Sciences & Pharmasset & Emory University & Patent \\
\hline $\begin{array}{l}6 / 28 / 2016 \\
(\# 208341)\end{array}$ & $\begin{array}{l}\text { Sofosbuvir, } \\
\text { velpatasvirt }\end{array}$ & Gilead Sciences & Pharmasset & Emory University & Patent \\
\hline $\begin{array}{l}3 / 13 / 2017 \\
(\# 209092)\end{array}$ & $\begin{array}{l}\text { Ribociclib } \\
\text { succinate }\end{array}$ & Novartis Pharms & Astex Therapeutics & University of Cambridge & Patent \\
\hline $\begin{array}{l}6 / 19 / 2017 \\
(\# 208610)\end{array}$ & $\begin{array}{l}\text { Delafloxacin } \\
\text { meglumine }\end{array}$ & Melinta & Melinta & Yale University & Patent \\
\hline $\begin{array}{l}7 / 18 / 2017 \\
(\# 209195)\end{array}$ & $\begin{array}{l}\text { Sofosbuvir, velpatasvir, } \\
\text { voxilaprevirt }\end{array}$ & Gilead Sciences & Pharmasset & Emory University & Patent \\
\hline
\end{tabular}

*Both etravirine and rilpivirine are non-nucleoside reverse transcriptase inhibitors and are successors to the TIBO compound discovered at the Rega Institute. This discovery led to the spin-off company Tibotec (later bought by Johnson and Johnson and merged with its Janssen division). The Orange Book patents were held by Janssen.

tLedipasvir, velpatasvir, and voxilaprevir are all new molecular entities approved as combination products with a sofosbuvir backbone. Sofosbuvir originated at the spin-off company Pharmasset, and therefore each of these combination products are considered to have a spin-off origin.

Book patent held by a publicly supported research institution or spin-off company, 27 (77\%) had at least one patent held on the key properties of the drug's

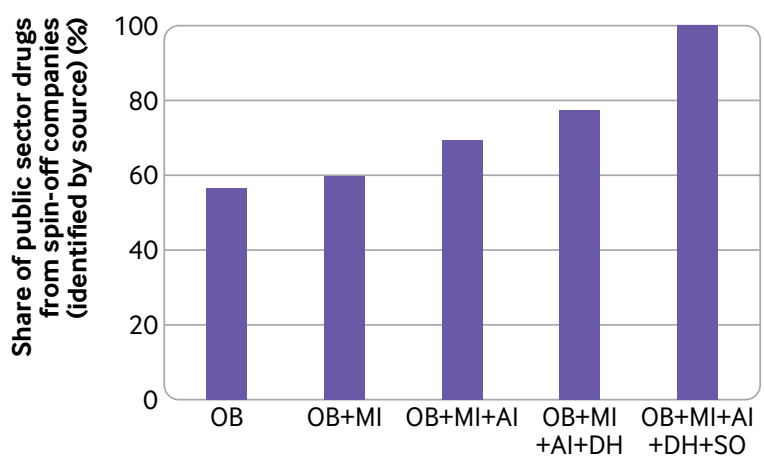

Fig 1 | Proportion of new drugs with publicly sponsored research or from spin-off companies, identified by data source. The figure shows the breakdown of the relative share of the data sources used to identify publicly supported research contributions. The first four columns represent the drugs identified as having public sponsored research origins, and the last column represents those with spin-off company origins. Most drugs identified as publicly supported research contributions had Orange Book patents assigned to either to a public sector institution (28/62) or spin-off company (an additional 7/62). Two more drugs were primarily identified by Merck Index patents, six by AdisInsight entries, and five by the authors' investigation of the drug's history. Finally, 14 drugs were identified as originating in a spin-off company. For the spin-off drugs, 12 had Orange Book patents held by the spin-off company (the remaining two had Orange Book patents held by the successor company of the spin-off). $O B=0$ range book; $\mathrm{MI}=$ Merck Index; $\mathrm{Al}=$ AdisInsight; $\mathrm{DH}=$ drug history (author's investigation); SO=spin-off company product or substance. Similar findings applied to drugs with late stage contributions from a spin-off company (table 4).

\section{FDA approval process}

New drugs based on contributions from publicly supported research or spin-off companies were substantially more likely to receive FDA approval through one or more expedited development or review pathways than new drugs without these characteristics (68\% v 47\%, $\mathrm{P}=0.005)$ and to be first in class $(45 \%$ $v 26 \%, \mathrm{P}=0.007$; table 5). Both are indicators of potentially greater therapeutic importance.

\section{Discussion}

\section{Principal findings}

In the present study, we studied all new drugs approved by the FDA in 2008-17 to determine whether their patents or other late stage, drug discovery contributions documented origins in publicly supported research. The development of a new drug treatment is a complicated process. Important and costly contributions come from both the public and the private sectors, in varying proportions. Under current patent law, making a seminal discovery about an important drug target, or even taking development of a new approach almost to the point of creating a marketable product, are not sufficient to win intellectual property rights to the drug that emerges from this chain of research. However, an entity (usually 


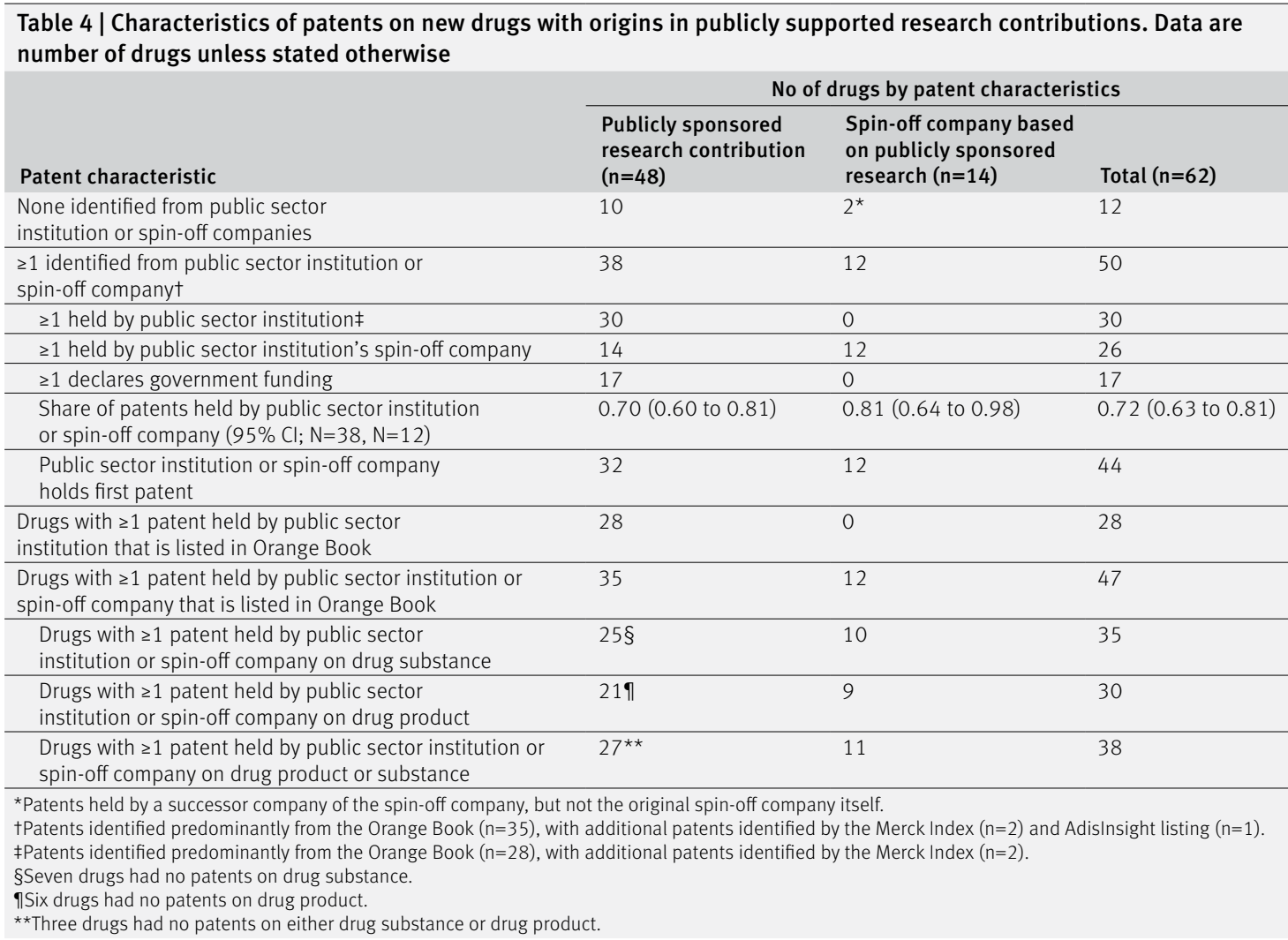

a pharmaceutical company) that performs these final steps is usually granted ownership over the product, and thus the chance to establish its price (in the US) and own the revenue it generates. Substantial private investment from industry is critical for many drugs for basic and clinical research, but by funding the clinical trials and the regulatory compliance necessary to win FDA approval, the role of the publicly supported research investments that served as the basis of the drug's discovery are often not as clearly attributed.

Our analysis found that publicly supported research in non-profit institutions (19\%) or spin-off companies that had their origins in public funded research $(6 \%)$ made important late stage intellectual contributions to at least one in four new drugs approved in the past decade. These data highlight the substantial and increasing role of late stage, publicly supported research in the development of new drugs (fig 2), ${ }^{43-15}$ in addition to the more widely acknowledged contributions of public funding to the foundational basic science discoveries on which most new products are based.

\section{Strengths and limitations of study}

This study had several limitations. Firstly, we identified a product as having a late stage, publicly supported research component if the patent and drug discovery history documented a key contribution by a public sector entity or spin-off company in its development. This method does not confirm that such public investment was the only source of a drug's creation, or that there was no private sector contribution. We did not attempt to weigh the relative importance of public versus private sector innovation for particular drugs; for many products, important corporate investment occurred as well. As a result, the substantial contributions of public support to late stage drug development would not confer partial public ownership of most of these products under current patent law. In fact, this flow of publicly funded research knowledge into the private sector for commercialization seems to have been a major goal of the original Bayh-Dole legislation, rather than an unintended consequence of it. ${ }^{25}$

Secondly, our analysis relies primarily on patents listed in the Orange Book and proprietary databases of drug development to identify public sector origins, which represents a limited set of patents associated with a drug, even though these patents are generally considered the most important in a product's intellectual genealogy. Further investigation into the origins of each drug might have yielded additional relevant information. This approach might underestimate the contributions of publicly supported and academically based researchers who collaborate with pharmaceutical companies if a patent derived from such collaboration is held by the sponsor. For example, Ciba-Geigy (now Novartis) held the patent for imatinib for years but had not developed the product clinically until Brian Drucker at Oregon Health and Science University persuaded the company to provide him with samples of it for his research on chronic myeloid leukemia, leading to the profitable product Gleevec, approved in 2001. ${ }^{26}$ Although that drug preceded the study period under consideration, the 


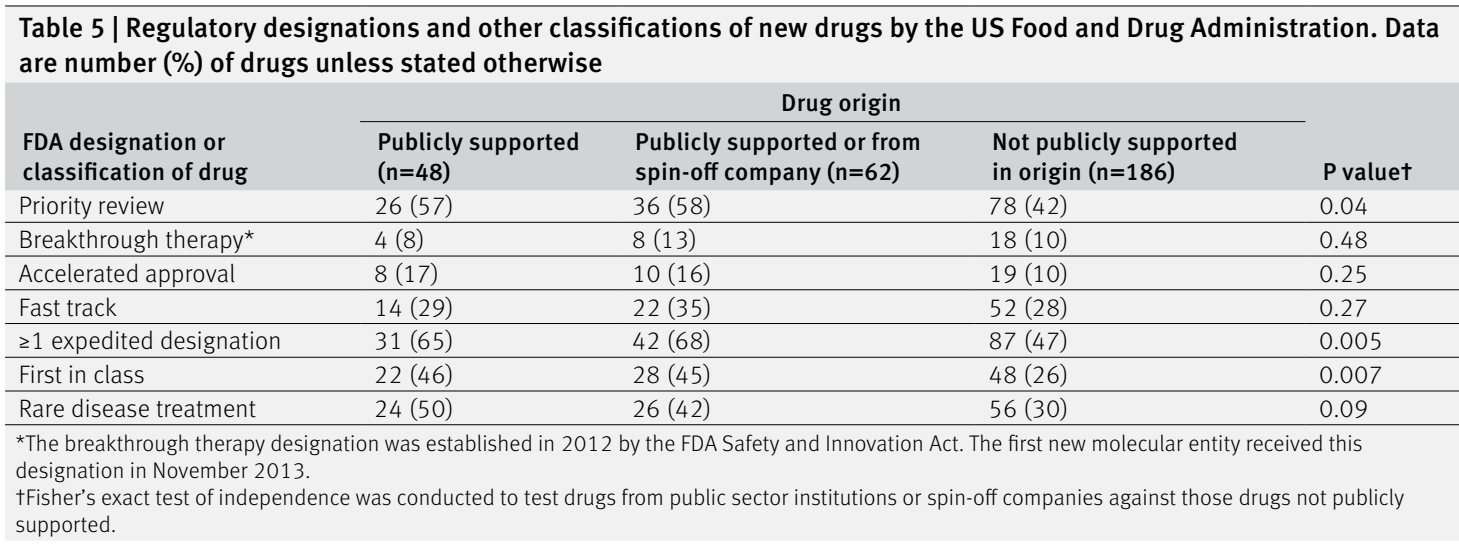

patents on the drugs were held by Novartis and there was no patent evidence held by (or royalty payments made to) the academic medical center that was essential in its development.

A third limitation is that we did not include biological agents in this study despite their clinical and economic importance. This exclusion was because the FDA does not collect patent data for drugs approved through the Biologic License Application process. Biological medicines represent an increasingly important component of drug treatment both clinically and economically, and the current regulatory framework limits the opportunity to produce generic drugs. Further research to investigate the role of late stage publicly supported research for biological medicines is necessary. Lastly, we limited our investigations to English language publications, websites, and media coverage to verify key contributions made by publicly supported research.

Our approach is not the only way of quantifying public sector research contributions, because it could miss a great deal of important scientific discovery funded and conducted with the support of public funding. The patent based approach used also underestimated the additional role of upstream basic and translational science research supported by public funds that is critical to the discovery of new drugs; this contribution has been clearly described by others. ${ }^{27}$ In addition, previous studies in the US and the UK have shown how publicly funded research create substantial direct and indirect economic value, complementing private industry research expenditure, innovation, and privately held patents. ${ }^{28} 29$ Thus, our approach does not capture the totality of returns generated as a result of public investment. ${ }^{30}$

Our analysis did not consider the relative amounts of financing that comes from public and private sector sources. We did not tabulate the cost of clinical development within industry required for final product development and regulatory approval, which can be substantial. We also did not consider the substantial public subsidies for the drug development enterprise, which include federal expenditures in the form of research and development tax credits and the Orphan

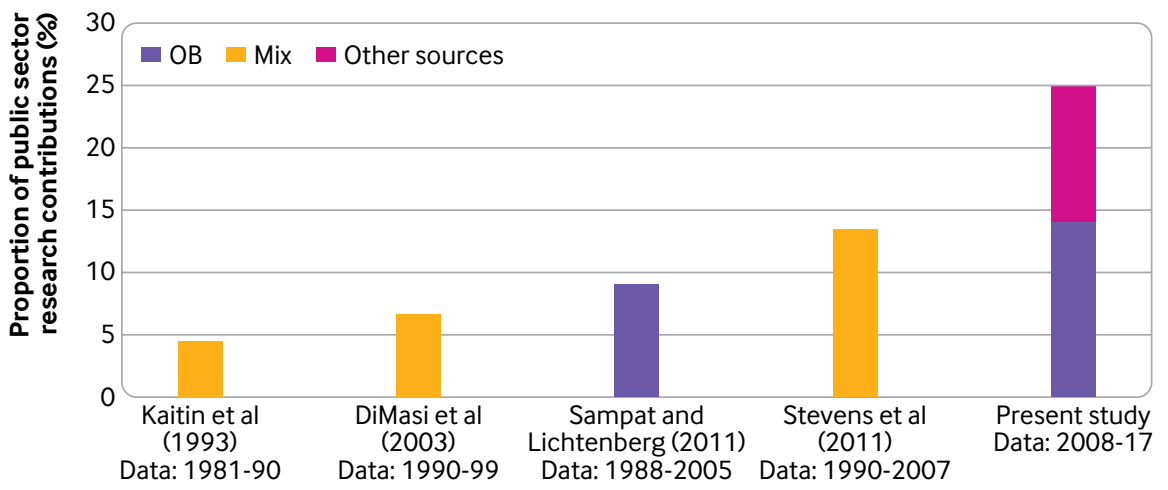

Fig 2 | Changes in rates of publicly sponsored research contributions to new drug discovery, by study over time with data sources used. The figure compares the present study with previous studies examining public sector contributions to new drug discovery via patent analysis. The Kaitin and DiMasi studies used the Tufts Center for the Study of Drug Development databases that use Orange Book patents as well as other proprietary datasets (not fully described). The analysis by Sampat and Lichtenberg examined patents listed only in the Orange Book. The Stevens et al study examined the Orange Book, proprietary licensing databases, and conducted a survey of university technology transfer managers to identify drugs that originated in public sector institutions. The relative contributions of the various sources were not disclosed, and how the studies dealt with contributions from public sector spin-off companies is not clear. However, the study period for Stevens et al was similar to that of Sampat and Lichtenberg, so the difference between their findings might be a result of the additional sources used. $\mathrm{OB}=0$ range $\mathrm{Book}$ 
Drug Act tax credit, which was a subsidy equal to $50 \%$ of the cost of the qualifying trial (until 2017, when it was reduced to $25 \%$ ). Our study also did not take into account direct funding of drug development in the form of publicly funded clinical trials as well as research and small business grants, and indirect support in the form of public sector research institutions hosting industry funded clinical trials.

\section{Comparison with other studies}

One difference between our analysis and previous studies is that earlier research relied predominantly on patent data provided in the FDA Orange Book, ${ }^{43-15}$ which could underestimate the role of publicly supported research if patents had expired at the time of drug approval, were never pursued, or were held by spin-off companies. Limiting our analysis to only those drugs with Orange Book patents held by public sector research institutions would have identified 28 drugs, or just $11 \%$ of new approvals (table 4 ). We would have missed, for example, an additional seven drugs that were ultimately determined to have publicly supported research origins, but the listed Orange Book patents were held by spin-off companies. Incorporating other patent sources, drug histories, and basic investigations to confirm a drug's development history, including the role of spin-off companies with origins in publicly support research, more accurately represents the late stage contributions of public sector funding to drug discovery and development.

These findings also reflect the continuing trend of an increasing role of publicly supported research in late stage research leading to new drug discovery, which has also been seen in previous studies (fig 2). ${ }^{4} 13-15$ This increasing trend might be because of ongoing congressional funding of biomedical research through the NIH since the 1990s. ${ }^{3132}$ The fruits of that earlier publicly supported research would be seen in recent drug approvals, because it typically takes a decade or more from drug discovery to approval. In addition, university-owned patents of all kinds have increased as a share of all US patents from $0.28 \%$ in 1969 to $0.83 \%$ in 1985 to $1.89 \%$ in $2012 .{ }^{33}$ This rising share reflects increased productivity as a result of more biomedical research funding as well as policies to more actively pursue patents by academic technology transfer offices in the nearly four decades since passage of the Bayh-Dole Act. ${ }^{34}$ For example, we identified at least 17 drugs for which US government interest was disclosed on patents; this number is likely to be an underestimate owing to evidence that government funding is underdisclosed on patent applications. ${ }^{93536}$ Because our study examined the assignee data on the patent grants, we would miss any updates submitted to the US Patent and Trademark Office of corrections clarifying government contributions. Recent analysis found these corrective updates to be as high as 20-30\% of all patents for some academic insitutions. ${ }^{37}$

Our data also indicate that drugs with contributions from publicly supported research or spin-off companies are 1.4 times as likely to receive an expedited FDA approval process and 1.7 times as likely to be first in class (table 5). Although these data are crude measures of innovativeness, they suggest that publicly supported research is not only leading to new drugs but also leading to new classes of drugs with novel mechanisms of action, a finding consistent with previous studies. ${ }^{15} 2938-40$

\section{Policy implications}

These findings have several implications for healthcare and regulatory policy, particularly in the US. The US biomedical enterprise underlies a substantial proportion of new drug development, ${ }^{41}$ although by no means all of it. ${ }^{42}$ At the same time, drug prices are substantially higher in the US than anywhere else in the world, with Americans paying on average about twice the per capita amount for prescription drugs as citizens of other advanced industrialized contries. ${ }^{43} 44$ Identification of drugs with late stage, publicly supported research contributions, particularly those for which such institutions hold key patents, could represent a useful policy lever. Such drugs include nusinersen (Spinraza, for spinal muscular atrophy; list price US\$750000 (£610400; €685000) in the first year of use), ${ }^{45}$ eliglustat (Cerdelga, for Gaucher disease; \$310 250/year), ${ }^{46}$ and enzalutamide (Xtandi, for prostate cancer; $\$ 129000 /$ year). ${ }^{47}$ The prices of these drugs, each of which relied on substantial academic development, have been criticized in the US and all are substantially lower in other countries.

For these and other drugs, the contributions of publicly funded research to their development could be expected to be compensated by more favorable pricing to payors, the largest of which is the US government itself. Although the university that largely developed Xtandi did receive a lucrative licensing agreement, such compensation is often not the case. Whether such payments-most of them far less lucrative-represent adequate compensation to the innovator institution for its role in drug development is unclear. ${ }^{48}$ In addition, such agreements when they exist do not benefit those who purchase these drugs at such high prices. Beside commercial insurers and state governments, such payors include the federal government and patients themselves-all of whom have already made investments into a drug's creation, such as through taxpayer support of NIH funding. ${ }^{49} 50$ Given the current US debate on whether the public is getting a fair return on public investment ${ }^{51}$ and when rising drug prices are defended as being necessary to fund industry innovation, without which new treatments would be expected to slow dramatically, our findings can inform this public discussion.

In theory, the US government retains a fully paid license, as well as so-called march-in rights, for patents with government funded origins. These provisions could allow the government to use the patented product for its own purposes or, in the case of march-in rights, grant additional licenses to others if needed to address health needs. Raising the prospect of using these authorities has had some effect in cases in which the NIH helped negotiate agreements 
on the licensing of stem cell patents. In addition, the US Centers for Disease Control and Prevention was able to liberalize the licensing of patents related to avian flu, and the manufacturer of ritonavir reduced a planned price increase for government agencies after a march-in petition was submitted to the NIH. ${ }^{52}$ But to our knowledge, neither authority has ever been activated by a federal agency for any drug, even in the face of critical drug shortages or extreme price spikes. ${ }^{8}$ Of course, these legal authorities, even if they were ever to be exercised, would only apply to drugs for which government patent rights can be identified. Government interest statements are underdisclosed and this study represents only a limited patent landscape analysis for each drug; thus, only a subset of drugs with public sector contributions in this study had definitively identified US government interests.

However, hundreds of public sector institutions have recognized their ethical obligation to make technology transfer agreements that will promote the public's interest and equitable access to medicines, although how well these principles are practiced by many institutions is unclear. ${ }^{10-12}$ While these technology transfer principles were developed and implemented primarily to promote access in low and middle income countries, this approach could also be used to ensure the public has access to very costly taxpayer funded drugs. Additionally, other broadly applicable policy tools might be available, such as negotiating lower drug prices (currently not in practice in the US) or even issuing compulsory licenses to meet public health needs regardless of drug origin or patent ownership, although greater justifications for the use of such interventions might be needed for high priced drugs with identified public sector contributions.

\section{Conclusion}

We reviewed comprehensive patent and related data to trace the intellectual contributions of publicly supported research to the discovery and development of new drugs. Our findings highlight the important role of public and philanthropic funding in the drug research and development ecosystem. We found that such institutions and their corporate spin-off companies were central to the development of at least a quarter of all new drugs approved by the FDA in 2008-17, either through direct contributions to drug development or through the formation of spinoff companies based on earlier public funding. Drugs approved following major public sector funding were more likely to receive an expedited development or approval pathway designation from the FDA and more likely to be a first-in-class treatment, suggesting that they were more likely to be novel and potentially clinically important.

Our findings also document a substantial increase in the share of drugs in the US with publicly supported research origins compared with previous studies. This increased share could reflect our more comprehensive methodological approach as well as growing taxpayer funding for biomedical research and increased pursuit of patents by public supported research institutions over the past few decades. These findings provide additional data for the ongoing debate on support for public sector biomedical research, and the best ways to take these key contributions into account in determining the ownership of and fair prices for new drugs, especially those priced at very high levels.

We thank ChangWon C Lee (Brigham and Women's Hospital/Harvard Medical School) for his research assistance in the revision process.

Contributors: RKN contributed to the design, conduct, analysis, and interpretation of results; JA contributed to the design and interpretation of results; ASK contributed to the design and interpretation of results. All authors contributed to and approved the final manuscript. The authors had full access to all the data in the study and all authors shared final responsibility for the decision to submit for publication. RKN is guarantor. The corresponding author attests that all listed authors meet authorship criteria and that no others meeting the criteria have been omitted.

Funding: This work was supported by the Arnold Ventures, Open Society Foundations, and the Engelberg Foundation. ASK is also supported by the Harvard-MIT Center for Regulatory Science. The funders had no role in study design, data collection, data analysis, data interpretation, or writing of the report.

Competing interests: All authors have completed the ICMJE uniform disclosure form at http://www.icmje.org/coi_disclosure.pdf and declare: support from the Open Society Foundations, Arnold Ventures, Engelberg Foundation, and Harvard-MIT Center for Regulatory Science for the submitted work; no financial relationships with any organizations that might have an interest in the submitted work in the previous three years, and no other relationships or activities that could appear to have influenced the submitted work.

Ethical approval: This study was not submitted for institutional review board review because it is based on publicly available data and involved no health records ( 45 Code of Federal Regulations [CFR] 46.102).

Data sharing: No additional data available.

The lead author affirms that the manuscript is an honest, accurate, and transparent account of the study being reported; that no important aspects of the study have been omitted; and that any discrepancies from the study as planned (and, if relevant, registered) have been explained.

This is an Open Access article distributed in accordance with the Creative Commons Attribution Non Commercial (CC BY-NC 4.0) license, which permits others to distribute, remix, adapt, build upon this work non-commercially, and license their derivative works on different terms, provided the original work is properly cited and the use is noncommercial. See: http://creativecommons.org/licenses/by-nc/4.0/.

1 Spector JM, Harrison RS, Fishman MC. Fundamental science behind today's important medicines. Sci Transl Med 2018;10:438. doi:10.1126/scitranslmed.aaq1787

2 Galkina Cleary E, Beierlein JM, Khanuja NS, McNamee LM, Ledley FD. Contribution of NIH funding to new drug approvals 20102016. Proc Natl Acad Sci U S A 2018;115:2329-34. doi:10.1073/ pnas. 1715368115

3 Chakravarthy R, Cotter K, DiMasi J, Milne C-P. Wendel N. Public- and private-sector contributions to the research and development of the most transformational drugs in the past 25 years: from theory to therapy. Ther Innov Regul Sci 2016;50:759-68. doi:10.1177/2168479016648730

4 DiMasi JA, Hansen RW, Grabowski HG. The price of innovation: new estimates of drug development costs. J Health Econ 2003;22:151 85. doi:10.1016/S0167-6296(02)00126-1

5 DiMasi JA, Grabowski HG, Hansen RW. Innovation in the pharmaceutical industry: New estimates of R\&D costs. J Health Econ 2016:47:20-33. doi:10.1016/j.jhealeco.2016.01.012

6 Giaccotto C, Santerre RE, Vernon JA. Drug prices and research and development investment behavior in the pharmaceutical industry. J Law Econ 2005;48:195-214. doi:10.1086/426882

Avorn J. The $\$ 2.6$ billion pill--methodologic and policy considerations. N Engl J Med 2015;372:1877-9. doi:10.1056/ NEJMp 1500848

8 Treasure CL, Avorn J, Kesselheim AS. Do march-in rights ensure access to medical products arising from federally funded research? A qualitative study. Milbank Q 2015;93:761-87. doi:10.1111/14680009.12164 
9 Arno PS, Davis MH. Why don't we enforce existing drug price controls? The unrecognized and unenforced reasonable pricing requirements imposed upon patents deriving in whole or in part from federally funded research. Tulane Law Rev 2001.

10 Statement of principles and strategies for the equitable dissemination of medical technologies. 2009. https://ocr.yale.edu/ sites/default/files/files/StatementOfPrinciples.pdf

11 In the public interest: nine points to consider in licensing university technology. 2007. https://ocr.yale.edu/sites/default/files/files/ Points_to_Consider.pdf

12 National Researsch Council. Managing university intellectual property in the public interest The National Academies Press, 2011.

13 Kaitin KI, Bryant NR, Lasagna L. The role of the research-based pharmaceutical industry in medical progress in the United States. J Clin Pharmacol 1993;33:412-7. doi:10.1002/j.1552-4604.1993. tb04680.x

14 Sampat BN, Lichtenberg FR. What are the respective roles of the public and private sectors in pharmaceutical innovation? Health Aff (Millwood) 2011:30:332-9. doi:10.1377/hlthaff.2009.0917

15 Stevens AJ, Jensen JJ, Wyller K, Kilgore PC, Chatterjee S, Rohrbaugh $\mathrm{ML}$. The role of public-sector research in the discovery of drugs and vaccines. N Engl J Med 2011;364:535-41. doi:10.1056/ NEIMsa1008268

16 Drugs@FDA Data Files, U.S. Food and Drug Administration. https:// www.fda.gov/drugs/drug-approvals-and-databases/drugsfda-datafiles

17 Darrow JJ, Kesselheim AS. Drug development and FDA approval, 1938-2013. N Engl / Med 2014;370:e39. doi:10.1056/ NEJMp1402114

18 Lanthier M, Miller KL, Nardinelli C, WoodcockJ. An improved approach to measuring drug innovation finds steady rates of first-in-class pharmaceuticals, 1987-2011. Health Aff (Millwood) 2013;32:1433-9. doi:10.1377/hlthaff.2012.0541

19 The Merck Index. The Royal Society of Chemistry. https://www.rsc. org/merck-index

20 PatentsView. United States Patent and Trademark Office. www. patentsview.org/

21 Baker C. Patentsview: An R Client to the PatentsView API. https:// ropensci.github.io/patentsview/index.htm

22 Hernandez D. A new strategy to undermine big pharma's price gouging actually worked. Slate. $2017 \mathrm{https}$ ://slate.com/ technology/2017/09/inside-the-battle-to-approve-a-chagastreatment.html

23 US Food and Drug Administration. Summary review: new drug application 209570 for benzidazole. 2017. https://www.accessdata. fda.gov/drugsatfda docs/nda/2017/2095700rig1s000SumR.pdf

24 Eastman Q, Korschun H. Emory celebrates top biotech innovations. Emory News Cent 2012. http://news.emory.edu/stories/2012/03/ tech transfer highlights/campus.html

25 Markel H. Patents, profits, and the American people--the BayhDole Act of 1980. N Engl J Med 2013;369:794-6. doi:10.1056/ NEJMp1306553

26 Druker BJ. Perspectives on the development of imatinib and the future of cancer research. Nat Med 2009;15:1149-52. doi:10.1038/ nm1009-1149

27 Griesenauer RH, Moore R, Kinch MS. NIH Support for FDA-Approved Medicines. Cell Chem Biol 2017;24:1315-6. doi:10.1016/j. chembiol.2017.11.002

28 Sussex J, Feng Y, Mestre-Ferrandiz I, et al. Quantifying the economic impact of government and charity funding of medical research on private research and development funding in the United Kingdom. BMC Med 2016;14:32. doi:10.1186/s12916-016-0564-Z

29 Azoulay P, Graff Zivin JS, Li D, Sampat BN. Public R\&D investments and private-sector patenting: evidence from NIH funding rules. Rev Econ Stud 2019;86:117-52. doi:10.1093/restud/rdy034

30 Mazzucato M. The entrepreneurial state: debunking public vs. private sector myths. 2nd ed. Penguin Books, 2018.

31 Johnson JA, Sekar K. NIH Funding: FY1994-FY2019. Washington, DC 2018. https://fas.org/sgp/crs/misc/R43341.pdf

32 Cockburn I, Henderson R. Publicly funded science and the productivity of the pharmaceutical industry. In: Innovation Policy and the Economy, Volume 1 . National Bureau of Economic Research, 2001.

33 United States Patent and Trademark Office, Patent Technology Monitoring Team. US colleges and universites - utility patent grants, calendar years 1969-2012. Alexandria, VA. https://www.uspto.gov/ web/offices/ac/ido/oeip/taf/univ/univ_toc.htm
34 Mowery DC, Sampat BN, Ziedonis AA. Learning to patent: institutional experience, learning, and the characteristics of US university patents after the Bayh-Dole Act 1981-1992. Manage Sci 2002:48:73-89. doi:10.1287/mnsc.48.1.73.14278

35 Rai AK, Sampat BN. Accountability in patenting of federally funded research. Nat Biotechnol 2012:30:953-6. doi:10.1038/nbt.2382

36 Government Accountability Office. Technology transfer: reporting requirements for federally sponsored inventions need revision. Washington, DC: 1999. https://www.gao.gov/archive/1999/ rc99242.pdf

37 Love J. Errors in patent grants: more common in medical patents. Bill of Health. http://blog.petrieflom.law.harvard.edu/2017/10/21/ errors-in-patent-grants-more-common-in-medical-patents/

38 Kesselheim AS, Tan YT, Avorn J. The roles of academia, rare diseases, and repurposing in the development of the most transformative drugs. Health Aff (Millwood) 2015;34:286-93. doi:10.1377/ hlthaff.2014.1038

39 Chakravarthy R, Cotter K, DiMasi J, Milne CP, Wendel N. Public- and private-sector contributions to the research and development of the most transformational drugs in the past 25 years: from theory to therapy. Ther Innov Regul Sci 2016;50:759-68. doi:10.1177/2168479016648730

40 Sampat BN, Lichtenberg FR. What are the respective roles of the public and private sectors in pharmaceutical innovation? Health Aff (Millwood) 2011;30:332-9. doi:10.1377/hlthaff.2009.0917

41 Kneller R. The importance of new companies for drug discovery: origins of a decade of new drugs [correction in: Nat Rev Drug Discov 2010;9:955.]. Nat Rev Drug Discov 2010;9:867-82. doi:10.1038/ $\operatorname{nrd} 3251$

42 Light DW, Lexchin J. Foreign free riders and the high price of US medicines. BMJ 2005;331:958-60. doi:10.1136/ bmj.331.7522.958

43 Kesselheim AS, Avorn J, Sarpatwari A. The high cost of prescription drugs in the United States: origins and prospects for reform. JAMA 2016;316:858-71. doi:10.1001/jama.2016.11237

44 Sarnak DO, Squires D, Bishop S. Paying for prescription drugs around the world: why is the US an outlier? 2017. https://www. commonwealthfund.org/publications/issue-briefs/2017/oct/paying prescription-drugs-around-world-why-us-outlier

45 Apleby J. Drug puts a $\$ 750,000$ "price tag on life". Kaiser Health News. 2017. https://khn.org/news/drug-puts-a-750000-price-tagon-life/

46 Weisman R. New Genzyme pill will cost patients \$310,250 a year. Boston Globe. 2014 (https://www.bostonglobe.com/ business/2014/09/02/new-genzyme-pill-treat-rare-gaucherdisease-will-cost-patients-year/5thklb587nKi7zRAb9GgxM/story. html)

47 Johnson C. Taxpayers helped fund this $\$ 129,000$ cancer drug. Should the government help cut the price? Washington Post. 2016. https://www.washingtonpost.com/news/wonk/wp/2016/01/14/ taxpayers-helped-fund-this-129000-cancer-drug-should-thegovernment-help-cut-the-price/

48 Valdivi WD. University start-ups: critical for improving technology transfer. Center for Technology Innovation at Brookings, 2013 https://www.brookings.edu/wp-content/uploads/2016/06/Valdivia_ Tech-Transfer v29 No-Embargo.pdf.

49 Engelberg AB, Kesselheim AS. Use the Bayh-Dole Act to lower drug prices for government healthcare programs. Nat Med 2016;22:576. doi:10.1038/nm0616-576

50 Pear R. 'Paying twice': a push for affordable prices for taxpayerfunded drugs. New York Times. 2018 https://www.nytimes. com/2018/05/28/us/politics/drug-prices.html

51 Mazzucato M, Roy V. Rethinking value in health innovation: from mystifications towards prescriptions. November, 2017. https://www ucl.ac.uk/bartlett/public-purpose/publications/2018/jan/rethinking value-health-innovation-mystifications-towards-prescriptions

52 KEl Comments Regarding the NIST Special Publication 1234 Draft Green Paper on Return on Public Investment. January, 2018. https:// www.keionline org/wp-content/uploads/2019/01/KEl-commentsNIST-SP-1234-ROl-9lan2018.pdf

Web appendix 1: Detailed explanation for including drugs with publicly supported and spinoff contributions

Web appendix 2: Data sources

Web appendix 3: Supplementary tables 